\title{
Psychological Resilience and Violence Tendency Levels of High School Adolescents Who Doing Team and Individual Sports
}

\author{
Tamer Karademir ${ }^{*}$, Ökkeş Alpaslan Gençay \\ High School of Physical Education and Sports, Kahramanmaras Sutcu Imam University, Turkey
}

Received February 27, 2020; Revised March 28, 2020; Accepted April 19, 2020

Copyright $\odot 2020$ by authors, all rights reserved. Authors agree that this article remains permanently open access under the terms of the Creative Commons Attribution License 4.0 International License

\begin{abstract}
This research was conducted to examine the psychological resilience and violence tendency levels of adolescents who are dealing with team and individual sports. In total, 225 volunteer athletes (104 females and 121 males), who were in the 14-18 age group, participated in this study. The data were collected through the violence tendency scale and the psychological resilience scale form. According to the results of the research, it was observed that there were similarities in the psychological resilience and violence tendency levels of male and female athletes concerning the gender and the sports experience variables. It was concluded that the violence tendency levels of the adolescents dealing with team sports were higher compared to the ones dealing with individual sports; the violence tendency levels of the athletes playing in clubs were lower compared to the athletes without a license and playing in school teams, and the psychological resilience levels of the first group were higher than the second group. Additionally, it was concluded that there was a negative, linear, and low-level significant relationship between the violence tendency levels and psychological resilience levels of the athletes in the research group.
\end{abstract}

Keywords Violence Tendency, Psychological Resilience, Sports, Adolescent

\section{Introduction}

Within the lifetime of individuals, it is possible to have social, psychological, and economic problems at various levels. These problems are not only for adults but also for the adolescents. Adolescence has been described as the period in life when an individual is no longer a child, but not yet an adult. It is a period in which an individual undergoes enormous psychological and physical changes.
In addition, the adolescent experiences changes in social expectations and perceptions. Physical growth and development are accompanied by sexual maturation, often leading to intimate relationships. The individual's capability for abstract and critical thought also develops, along with a sense of self-awareness when social expectations require emotional maturity. It is important to keep this in mind for a more complete understanding of the behaviours of adolescents as you read through this handout [1].

International studies report that adolescents show more commonly behavioral problems [2]. However, while some adolescents can have difficulties in coping with these problems, some others can overcome these problems without being affected, or they can adapt to the situation and recover more quickly. The most fundamental factor that is effective in the adaptation process is the psychological resilience [3], which is a concept requiring the efforts of individuals, time, and continuity.

Psychological resilience is a broad and conceptual subject, which is the process of eliminating negative thoughts and ensuring positive adaptation instead [4], and regaining power against adverse events rather than being unharmed in the face of a simple stress [5]. Among the factors that increase psychological resilience are the teachers, group of friends, neighbors, and other relatives, who are helping individuals to overcome the difficulties [6], as well as the trainers and physical education teachers, who are always in an interaction with athletes during their sportive activities. In fact, physical education and sports affect human life with different motives from many different genres, revealing their moods [7]. Successes and failures in the development processes of young individuals, excessive intensive trainings and difficulties in struggle, mood changes such as stress and anxiety, and adaptation processes to overcome these changes, all of which are involved in sporting activities, are becoming important for 
trainers, educators, and parents. Sportive activities are the environments, where violence tendency can arise sometimes as learned behaviors, there is an intense will to fight and win, and irritations may be observed along with the frustrations.

The subject of violence is one of the concepts that is quite difficult to identify [8]. This is due to the fact that violence feeds on human thinking, it has versatile dimensions, and violence has a history as old as humanity. Therefore, while, as a phenomenon, through discussing and examining the violence concerning its sources, motives, dimensions, and emergence forms, it is not easy to define and classify a standard violence that is acceptable to any community at any time [9].

Violence can be defined as the form of aggression, in which negative emotions such as hatred, hate, and hostility gain more efficiency in an individual. The World Health Organization (WHO) defines the violence as "deliberate threat or use of physical force ending up with injury, death, psychological damage, frustration, or deprivation against another individual or a group or community". Violent behavior differs from person to person, based on its direction, severity, or type [10]. Considering that an individual applies violence while another individual doesn't in similar circumstances, it can be suggested that personal traits are effective in the violence tendency [11]. As per the violence tendency, it consists of violence-related emotions, thoughts, and behaviors of individuals. This concept is not limited to the violent behaviors of individuals; justifying the use of violence in any case is also a violence tendency as much as applying violence [12].

When the literature is examined, it is observed that the factors affecting the violence are classified in five basic categories. These are personal factors (personality disorder, impulsivity and hyperactivity, psychiatric disorders, aggression, and substance-use), family factors (domestic violence, child abuse and rejection, conflicts and poor family ties) [11], school factors (anti-social group of friends, low school loyalty, academic failure, large school, gang groups, isolation, peer group involving peer rejection and bullying), and social and environmental situational factors (power, images of violence in the media, easy access to weapons, biases against gender roles, and cultural norms) [13].

When the previous studies in this subject in the literature were examined, it was observed that generally the relationships were revealed between the psychological resilience and anxiety [14], depression [15], stress [16], life satisfaction [17], mental health [18], social support perception [19] and motivation in sports [20]. However, previous researches have not been specifically evaluated together the relationship between the psychological resilience and violence tendency on adolescent athletes. Therefore, we believe that our research contributes to general knowledge on this topic.

\subsection{Research Goal}

In the present study, it is aimed to determine the relationship between the psychological resilience levels and violence tendency levels of adolescent individuals, who are dealing with sports, and how it is shaped according to the addressed variables. Thus, by understanding how the adolescent athletes succeed, who have to cope with adverse circumstances of life and risky situations such as violence tendency and psychological bad-mood, and by understanding how they could stand as enduring individuals against all these adverse conditions threatening their healthy developments, will light the way for further studies on other children and young individuals under similar risks. Similar research could target improvements in resilience and cope with violence tendency amongst athletes as well.

\section{Materials and Methods}

In the study; since the relationships between dependent and independent variables were examined, the relational screening model was used.

\subsection{Sample Group}

The population of the study is Kahramanmaras and the sample group is limited to Kahramanmaras. The sample group was determined by convenience sampling method, whose sample group was comprised of 225 volunteer athletes (121 males and 104 females) in the 14-18 age group. The mean age of female is $15 \pm 1.25$ and the mean age of male is $15 \pm 2.14$. The athletes were adolescent individuals who were dealing with team sports (football $(n=30)$, volleyball $(n=32)$, basketball $(n=29))$ and individual sports (wrestling $(\mathrm{n}=27)$, boxing $(\mathrm{n}=20)$, athletics $(n=26)$, tennis $(n=28)$, taekwondo $(n=33))$.

\subsection{Data Collection}

The legal permissions were obtained from the ethics committee before starting the research. The data were collected through the personal information forms developed by the researchers, through the violence tendency scale and psychological resilience scale form. The scale forms were distributed to athletes at rest, where they train. The same procedure was applied for each athlete in different sports branches. Filling the scale forms took approximately 12 minutes for each athlete.

\subsubsection{Violence Tendency Scale}

The scale was developed, to be used in a research titled "Aggression and violence tendency levels of students at the secondary education level" on behalf of the Ministry of National Education. Subsequently, it was redesigned in accordance with its original form and its content validity 
was verified [21]. The reliability coefficient of the Violence tendency scale was calculated as .78 and .87 in two different times. As the conclusion of the Split Half test, the $1^{\text {st }}$ semi Alpha value was determined as .74 , the $2^{\text {nd }}$ semi Alpha value was determined as .81 , and the Spearman-Brown test result for the whole was determined as .86 [22]. There are five levels at the violence tendency scale as "I strongly agree", "I agree", "Neutral", "I disagree", and "I strongly disagree". These levels have certain scores as $+1,+2,+3,+4$, and +5 . Thus, the highest possible score to gain from this scale is $20 \times 5=100$ points, and the lowest is $20 \times 1=20$ points. Having (arithmetically) a high score demonstrates high tendency to violence, and having lower scores demonstrates lower level of tendency to violence. Cronbach's Alpha value was founded as 0.88 in this research.

\subsubsection{Psychological Resilience Scale}

The 28-item original form of the scale, which was developed based on the data collected from eleven different countries, is comprised of three subscales and eight sub-dimensions. The scale was developed from a socio-ecological standpoint, using qualitative and quantitative methods [23]. Short form of the scale was developed by Liebenberg, Ungar and LeBlanc [24], and a 12-item structure was obtained. Three iterations of an Exploratory Factor Analysis were conducted on data from the first sample of youth to identify items for inclusion in the CYRM-12. In the third analysis, a varimax rotated factor analysis of the 12 items resulted in a four-factor solution, with 10 of the items loading well. Reliability of this grouping of questions is satisfactory $(\alpha=0.754)$. Confirmatory factor analysis was then conducted on the second sample of youth. A satisfactory fit was obtained $\left(\chi^{2}\right.$ $(51, \mathrm{~N}=1540)=255.419, \mathrm{p}=0.0001$; Adjusted Goodness of Fit Index $=0.960$; Comparative Fit Index $=0.957$; Root Mean Square Error of Approximation $=0.050$ ). Cronbach's
Alpha for the 12 items was also satisfactory $(\alpha=0.840)$. The scale, whose Turkish reliability and validity tests were conducted by Arslan [25]. The exploratory and confirmatory factor analysis results indicated that a total of $51.28 \%$ the variance was accounted for by a factor, was a five point likert scale graded between "It definitely defines me (5)" and "It definitely doesn't define me (1)". Short form (12-item) was used in this research. The internal consistency coefficient of the scale was determined as 0.91 . Higher scores demonstrate higher level of psychological resilience. Cronbach's Alpha value was founded as 0.89 in this research.

\subsubsection{Analyzing of Data}

The data obtained in the research were analyzed through the SPSS 21 package program. Before conducting the statistical analyses, it was tested through Kolmogorov Smirnov and Levene tests whether the distribution of the data was normal. It was determined that it was not normally distributed for some variables. The t-test was used in the paired comparisons of the independent variables of the parametric data. The paired comparisons of non-parametric data variables were employed through the Mann Whitney $\mathrm{U}$ test, while the multiple group comparisons were analyzed through the Kruskal Wallis tests. Whether there was a relationship between the violence tendency and psychological resilience, in other words, the dependent variable was tested through the Spearman correlation test. The significance levels of the results were accepted as $p<0.05$.

\section{Findings}

The data obtained from the sample group were analyzed through proper test methods and presented in the following tables.

Table 1. Analysis results of the sample group concerning the gender variable (t-test)

\begin{tabular}{|c|c|c|c|c|c|c|}
\hline & Gender & $\mathrm{N}$ & Mean & SD & $\mathrm{t}$ & Sig. \\
\hline \multirow{2}{*}{ Violence tendency } & Male & 121 & 55.90 & 11.36 & \multirow{2}{*}{1.133} & \multirow{2}{*}{.258} \\
\hline & Female & 104 & 54.15 & 11.82 & & \\
\hline \multirow{2}{*}{ Psychological resilience } & Male & 121 & 49.00 & 9.19 & \multirow{2}{*}{-1.378} & \multirow{2}{*}{.170} \\
\hline & Female & 104 & 50.49 & 6.45 & & \\
\hline
\end{tabular}


According to the Table 1, it was determined that there was statistically no significant difference in the violence tendency and psychological resilience levels of the sample group concerning the gender variable.

Table 2. Analysis results of the sample group concerning the sports branch variable (t-test)

\begin{tabular}{|l|l|c|c|c|c|c|}
\hline & Sports branch & $\mathrm{N}$ & Mean & SD & $\mathrm{t}$ & Sig. \\
\hline \multirow{3}{*}{ Violence tendency } & Individual sports (wrestling-boxing-athletics-tennis-taekwondo) & 77 & 52.92 & 11.97 & \multirow{2}{*}{-2.045} & \multirow{2}{*}{$.042 *$} \\
\cline { 2 - 6 } & Team sports (football-volleyball-basketball) & 148 & 56.22 & 11.25 & & \\
\hline \multirow{2}{*}{ Psychological resilience } & Individual sports (wrestling-boxing-athletics-tennis-taekwondo) & 77 & 49.63 & 7.69 & \multirow{2}{*}{-.076} & \multirow{2}{*}{.939} \\
\cline { 1 - 5 } & Team sports (football-volleyball-basketball) & 148 & 49.72 & 8.27 & & \\
\hline
\end{tabular}

$* \mathrm{p}<0.05$

According to the Table 2, it was determined that there were statistically significant differences in the violence tendency levels of the sample group concerning the sports branch variable $(\mathrm{t}=-2.045 ; \mathrm{p}<0.05)$, while there was no difference concerning the psychological resilience levels ( $t=-.076 ; \mathrm{p}>0.05)$.

Table 3. Analysis results of the sample group concerning the sports experience variable (Kruskal Wallis)

\begin{tabular}{|c|c|c|c|c|c|c|}
\hline & Sports experience & $\mathrm{N}$ & Mean & SD & $\mathrm{X}^{2}$ & Sig. \\
\hline \multirow{3}{*}{ Violence tendency } & 1-3 Years & 167 & 55.51 & 11.65 & \multirow{3}{*}{2.579} & \multirow{3}{*}{.275} \\
\hline & 4-6 Years & 36 & 52.58 & 10.86 & & \\
\hline & $7+$ & 22 & 56.04 & 12.20 & & \\
\hline \multirow{3}{*}{ Psychological resilience } & 1-3 Years & 167 & 50.04 & 7.90 & \multirow{3}{*}{2.149} & \multirow{3}{*}{.341} \\
\hline & 4-6 Years & 36 & 49.88 & 7.32 & & \\
\hline & $7+$ & 22 & 46.68 & 9.96 & & \\
\hline
\end{tabular}

According to the Table 3, it was determined that there was statistically no significant difference in the violence tendency and psychological resilience levels of the sample group concerning the sports experience variable.

Table 4. Analysis results of the sample group concerning the being an athlete variable (Kruskal Wallis)

\begin{tabular}{|c|c|c|c|c|c|c|c|}
\hline & Being an athlete & $\mathrm{N}$ & Mean & SD & $\mathrm{X}^{2}$ & Sig. & Diff. U test \\
\hline \multirow{5}{*}{ Violence tendency } & 1.School team & 48 & 57.64 & 12.70 & \multirow{5}{*}{12.185} & \multirow{5}{*}{$.016^{*}$} & \multirow{5}{*}{$2<1,4$} \\
\hline & 2.Club athlete & 12 & 46.58 & 12.62 & & & \\
\hline & 3. Licensed athlete & 26 & 53.92 & 11.05 & & & \\
\hline & 4. No license & 35 & 59.34 & 10.65 & & & \\
\hline & 5.Other & 104 & 53.76 & 10.70 & & & \\
\hline \multirow{5}{*}{ Psychological resilience } & 1.School team & 48 & 50.68 & 9.31 & \multirow{5}{*}{12.907} & \multirow{5}{*}{$.012 *$} & \multirow{5}{*}{$2>3,4,5$} \\
\hline & 2.Club athlete & 12 & 54.50 & 5.26 & & & \\
\hline & 3. Licensed athlete & 26 & 47.38 & 7.40 & & & \\
\hline & 4. No license & 35 & 48.88 & 9.24 & & & \\
\hline & 5.Other & 104 & 49.52 & 7.24 & & & \\
\hline
\end{tabular}

$* \mathrm{p}<0.05$

According to the Table 4 , it was determined that there were statistically significant differences in the violence tendency levels $\left(X^{2}=12.185 ; p<0.05\right)$ and psychological resilience levels $\left(X^{2}=12.907 ; p<0.05\right)$ of the sample group concerning the being an athlete variable. In the test applied to determine the source of the difference, it was determined that this difference aroused from the club athletes. 
Table 5. Analysis results of the sample group concerning the friendship relations variable (Kruskal Wallis)

\begin{tabular}{|c|c|c|c|c|c|c|c|}
\hline & Friendship relations & $\mathrm{N}$ & Mean & SD & $\mathrm{X}^{2}$ & Sig. & $\begin{array}{l}\text { Diff. } \\
\text { U test }\end{array}$ \\
\hline \multirow{4}{*}{ Violence tendency } & 1. $\mathrm{Bad}$ & 8 & 53.87 & 9.29 & \multirow{4}{*}{.962} & \multirow{4}{*}{.810} & \\
\hline & 2. Medium & 21 & 56.33 & 11.65 & & & \\
\hline & 3. Good & 69 & 55.73 & 11.66 & & & \\
\hline & 4. Very good & 127 & 54.62 & 11.75 & & & \\
\hline \multirow{4}{*}{ Psychological resilience } & 1. Bad & 8 & 44.87 & 7.23 & \multirow{4}{*}{15.642} & \multirow{4}{*}{$.001 *$} & \multirow{4}{*}{$1<3,4$} \\
\hline & 2. Medium & 21 & 46.33 & 6.87 & & & \\
\hline & 3. Good & 69 & 49.24 & 7.43 & & & \\
\hline & 4. Very good & 127 & 50.79 & 8.40 & & & \\
\hline
\end{tabular}

$* \mathrm{p}<0.05$

According to the Table 5, it was determined that there was statistically no significant difference in the violence tendency levels, while there were statistically significant differences in psychological resilience levels $\left(X^{2}=15.642\right.$; $\mathrm{p}<0.05$ ) of the sample group concerning the friendship relations variable. In the test applied to determine the source of the difference, it was determined that this difference aroused from the group considering the friendship relations negative.

Table 6. Analysis results of the sample group concerning the sports motivator variable (Kruskal Wallis)

\begin{tabular}{|c|c|c|c|c|c|c|c|}
\hline & Sports motivator & $\mathrm{N}$ & Mean & SD & $\mathrm{X}^{2}$ & Sig. & Diff. U test \\
\hline \multirow{5}{*}{ Violence tendency } & 1.Physical education teacher & 97 & 55.04 & 11.25 & \multirow{5}{*}{14.887} & \multirow{5}{*}{$.005^{*}$} & \multirow{5}{*}{$3<1,2,4,5$} \\
\hline & 2. My friends & 34 & 57.20 & 10.29 & & & \\
\hline & 3. My family & 32 & 48.81 & 10.14 & & & \\
\hline & 4. Sample athletes & 39 & 56.23 & 12.55 & & & \\
\hline & 5. Television - internet & 23 & 59.04 & 12.49 & & & \\
\hline \multirow{5}{*}{ Psychological resilience } & 1.Physical education teacher & 97 & 49.77 & 8.23 & \multirow{5}{*}{2.470} & \multirow{5}{*}{.650} & \\
\hline & 2. My friends & 34 & 47.97 & 9.00 & & & \\
\hline & 3. My family & 32 & 49.59 & 8.96 & & & \\
\hline & 4. Sample athletes & 39 & 51.02 & 6.63 & & & \\
\hline & 5. Television - internet & 23 & 49.78 & 6.81 & & & \\
\hline
\end{tabular}

$* \mathrm{p}<0.05$

According to the Table 6, it was determined that there were statistically significant differences in the violence tendency levels in favor of the ones mentioned "my family" $\left(X^{2}=14.887 ; \mathrm{p}<0.05\right)$, while there were statistically no significant differences in psychological resilience levels $\left(X^{2}=2.470 ; p>0.05\right)$ of the sample group concerning the sports motivator variable.

Table 7. Analysis results of the sample group concerning the reason behind sports variable (Kruskal Wallis)

\begin{tabular}{|c|c|c|c|c|c|c|c|}
\hline & Reason behind sports & $\mathrm{N}$ & Mean & SD & $\mathrm{X}^{2}$ & Sig. & Diff. U test \\
\hline \multirow{5}{*}{ Violence tendency } & 1. Being Healthy & 128 & 53.71 & 11.70 & \multirow{5}{*}{10.359} & \multirow{5}{*}{$.035^{*}$} & \multirow{5}{*}{$4>1,2$} \\
\hline & 2.Obtaining a profession & 15 & 50.80 & 7.45 & & & \\
\hline & 3. To be champion & 17 & 55.17 & 12.31 & & & \\
\hline & 4. Being Famous & 10 & 61.80 & 9.75 & & & \\
\hline & 5.Other & 55 & 57.49 & 11.25 & & & \\
\hline \multirow{5}{*}{ Psychological resilience } & 1. Being Healthy & 128 & 50.76 & 7.63 & \multirow{5}{*}{5.755} & \multirow{5}{*}{.218} & \\
\hline & 2.Obtaining a profession & 15 & 47.86 & 9.54 & & & \\
\hline & 3. To be champion & 17 & 47.29 & 10.61 & & & \\
\hline & 4. Being Famous & 10 & 48.70 & 7.57 & & & \\
\hline & 5.Other & 55 & 48.61 & 7.67 & & & \\
\hline
\end{tabular}

$* \mathrm{p}<0.05$ 
According to the Table 7, it was determined that there were statistically significant differences in the violence tendency levels $\left(X^{2}=10.359 ; p<0.05\right)$, while there was no difference in psychological resilience levels $\left(X^{2}=5.755 ; p>0.05\right)$ of the sample group concerning the reason behind sports variable. In the test applied to determine the source of the difference, it was determined that this difference aroused from the group, who mentioned that they do sports for becoming famous.

Table 8. Analysis results of the sample group concerning the father attitude variable (Kruskal Wallis)

\begin{tabular}{|c|c|c|c|c|c|c|c|}
\hline & Father attitude & $\mathrm{N}$ & Mean & SD & $\mathrm{X} 2$ & Sig. & Diff. U test \\
\hline \multirow{4}{*}{ Violence tendency } & 1. Protective & 103 & 54.94 & 10.41 & \multirow{4}{*}{4.188} & \multirow{4}{*}{$.007^{*}$} & \multirow{4}{*}{$2>1,3,4$} \\
\hline & 2. Authoritarian & 33 & 60.63 & 11.46 & & & \\
\hline & 3. Democratic & 29 & 54.24 & 11.61 & & & \\
\hline & 4. Affectionate & 60 & 52.03 & 12.31 & & & \\
\hline \multirow{4}{*}{ Psychological resilience } & 1. Protective & 103 & 50.44 & 7.96 & \multirow{4}{*}{5.742} & \multirow{4}{*}{$.001 *$} & \multirow{4}{*}{$2<1,3,4$} \\
\hline & 2. Authoritarian & 33 & 44.84 & 9.14 & & & \\
\hline & 3. Democratic & 29 & 48.79 & 5.30 & & & \\
\hline & 4. Affectionate & 60 & 51.50 & 7.78 & & & \\
\hline
\end{tabular}

$* \mathrm{p}<0.05$

According to the Table 8, it was determined that there were statistically significant differences in the violence tendency levels $\left(\mathrm{X}^{2}=4.188 ; \mathrm{p}<0.05\right)$ and psychological resilience levels $\left(\mathrm{X}^{2}=5.742 ; \mathrm{p}<0.05\right)$ of the sample group concerning the father attitude variable. In the test applied to determine the source of the difference, it was determined that this difference aroused from the group, whose father attitude was authoritarian.

Table 9. Analysis results of the sample group concerning the mother attitude variable (Kruskal Wallis)

\begin{tabular}{|c|c|c|c|c|c|c|}
\hline & Mother attitude & $\mathrm{N}$ & Mean & SD & $X^{2}$ & Sig. \\
\hline \multirow{4}{*}{ Violence tendency } & 1. Protective & 76 & 55.22 & 11.71 & \multirow{4}{*}{2.653} & \multirow{4}{*}{.448} \\
\hline & 2. Authoritarian & 21 & 58.57 & 11.38 & & \\
\hline & 3. Democratic & 18 & 53.22 & 9.44 & & \\
\hline & 4. Affectionate & 110 & 54.27 & 11.65 & & \\
\hline \multirow{4}{*}{ Psychological resilience } & 1. Protective & 76 & 49.28 & 7.74 & \multirow{4}{*}{1.696} & \multirow{4}{*}{.638} \\
\hline & 2. Authoritarian & 21 & 48.33 & 8.86 & & \\
\hline & 3. Democratic & 18 & 50.27 & 6.40 & & \\
\hline & 4. Affectionate & 110 & 50.13 & 8.40 & & \\
\hline
\end{tabular}

According to the Table 9, it was determined that there was statistically no significant difference in the violence tendency and psychological resilience levels of the sample group concerning the mother attitude variable.

Table 10. Correlation analysis results of the sample group concerning their violence tendency and psychological resilience levels

\begin{tabular}{|c|c|c|c|c|}
\hline & & & 1 & 2 \\
\hline \multirow{6}{*}{ Spearman's rho } & \multirow{3}{*}{ Violence tendency } & Correlation Coefficient & 1.000 & $-.219^{*}$ \\
\hline & & Sig. (2-tailed) & . & .001 \\
\hline & & $\mathrm{N}$ & 225 & 225 \\
\hline & \multirow{3}{*}{ Psychological resilience } & Correlation Coefficient & $-.219^{*}$ & 1.000 \\
\hline & & Sig. (2-tailed) & .001 & . \\
\hline & & $\mathrm{N}$ & 225 & 225 \\
\hline
\end{tabular}


According to the Table 10, it was determined that there was a low-level, negative, and linear correlation between the average scores of the violence tendency and psychological resilience levels of the sample group, and it was also determined that this relation was statistically significant $(\mathrm{r}=-.219 ; \mathrm{p}<0.05)$. Accordingly, it was observed that the higher the violence tendency level of the sample group, accordingly, the lower their psychological resilience levels, in other words, as their psychological resilience levels increased, their violence tendency levels decreased.

\section{Discussion}

The results of the study, which examined the psychological resilience and violence tendency levels of the adolescent athletes dealing with either team or individual sports, are evaluated in line with the findings of the literature. According to this;

Although it was determined that, concerning the gender variable, the average violence tendency levels of the females in the sample group were relatively lower and their average psychological resilience levels were higher, it was determined that this difference was statistically not significant (Table 1). In the literature, in some previous studies conducted on the adolescent students, it was determined that the psychological resilience scores of students were statistically significant in favor of female students [26]. Similarly, some other previous studies concluded that the psychological resilience levels of the primary school $8^{\text {th }}$ grader female students were higher compared to the males [27]. This result was explained by that females have responsibilities starting from early ages in Turkish culture, with high social expectations from them, which urge the females to cope with more problems. Additionally, there are previous studies conducted abroad demonstrating that males had higher violence tendency levels [28-30]. In a study conducted on male adolescents by Lopez and Emmer [31], it was observed that the sense of "masculinity" triggers violence in both physical-defensive fights and in gang-crimes. According to Thomas and Smith [32], it was observed that male students have higher levels of violence tendency and more open to provocations compared to the female students. It was reported that female students have more implicit types of violence rather than clear show of brute force. The research conducted by Rahmati and Naimikia [33] indicated that there is no significant difference between male and female athletes concerning the psychological resilience. This result supports the findings of our study. Additionally, composing the sample group only from individuals dealing with sports may also have an effect on revealing similar personal properties and creating no difference.

While it was determined that there was a statistically significant difference concerning the sports branch variable in the violence tendency levels, there was statistically no significant difference in the psychological resilience levels (Table 2), and there was statistically no significant difference concerning the sports experience among the dependent variables (Table 3 ).

Various previous research findings in the literature demonstrate that participation in sports has positive effects on psychological structure [34-37]. In a study conducted by Salar, Hekim and Tokgöz [38], it was aimed to examine the psychological characteristics of the athletes who are dealing with team and individual sports in the 15-18 age group. It was determined that individuals who regularly do sports at least 3-4 days a week are feeling emotionally very well. In the same study, the individuals dealing with both team and individual sports are determined to have a similar level of emotional wellness, and according to this result, it was determined that participation in both team and individual sports is useful in development of psychological health of young individuals. Because despite stressful environments, psychological resilience, which has a protective role, involves a process that can be learned [39]. In addition, the violence tendency level in team athletes was detected high. Violence tendency behavior is emerged through the influence of a large number of variables. Family behaviors [40] and watching violent films [12] might have a negative impact on aggression, and violence tendencies, while it is reported that people doing sports have more vibrant, hardworking and environmentally compatible personality features, and their psychological resilience increases [41-43].

It was observed that there were statistically significant differences in favor of the club athletes in the sample group concerning the being an athlete variable in violence tendency and psychological resilience levels (Table 4). Athletes in the sports club can have more training and competition experiences. In this process, they are subjected to difficulties in both physical and psychological terms. This increased experience also ensures the increase in their physical and psychological resilience, contributing to disciplining their violence tendency levels. In previous studies, it was suggested that psychological resilience is a process that changes over time [44] and this process increases through sports. In another study, it was determined that as the physical activity increased, psychological resilience increased as well [45]; in another research conducted on secondary education students, it was revealed that participation in sport increased psychological resilience [41]. In addition, findings demonstrating that having a license increases the violence tendency levels were reached [46].

It was determined that there was statistically no significant difference in the violence tendency levels of the sample group concerning the friendship relations variable, while there were statistically significant differences in psychological resilience levels in favor of the participants considering the friendship relations as "well" and "very 
well" (Table 5). Particularly during the adolescence, individuals can experience different emotional changes while continuing their search for self. In this process, in case of a problem, positive friendship relations can help move away the negative situation by providing psychological support. This can create a positive effect on their resilience while ensuring their psychological relief. Furthermore, research findings indicated that social contribution, career goals, patience, self-confidence, desire for learning, grit, spirituality, financial situation, host society support, family members support are protective factors against risks [47]. Koç Yıldırım et al., [26] emphasize that positive peer relationships have a positive effect on psychological resilience in addition to school support especially during adolescence.

In the study, it was determined that the violence tendency levels of the participants who were motivated for sports by their families were statistically significantly lower than those in other groups (Table 6). On the other hand, it was observed that the violence tendency levels of the ones, whose father attitudes were defined as authoritarian, were higher, whereas their psychological resilience levels were lower; as per the mother attitude, it was observed that this was not an influential factor (Table 8 and Table 9). In the literature, concerning the violence tendency, it was reported that the individuals, who experienced severe conflict in the family and have divorced parents, transfer the violence into their lives or doing sports for long years do not protect the athlete from violence, which settles into the characteristics of the personality [48]. A remarkable finding of this study was that the father attitude is effective on the violence tendency and psychological resilience of adolescents, while the mother attitude does not affect. At this point, the effect of fathers on children is an issue that should not be ignored. Although the healthy family relationship supports identity formation and psychological resilience [49], the obtained result demonstrates that children are positively or negatively influenced from the attitudes of their fathers.

In the study, the violence tendency levels of the group, who were doing sports for being famous, were higher compared to those, who were doing sports for being healthy or acquiring a profession; however, their psychological resilience levels were similar (Table 7). In recent years, sports have changed its way of application and have gained new meanings with different expressions. The aggression characteristic of an individual is transformed into peace-based relaxation through sports and it provides an appropriate competition medium for controlling instinctive aggression [50]. According to psychologists, what expected from participating in sports is to strengthen and popularize an individual's values to be future forms of behavior, and to find ways to solve the difficulties faced in one's life [51]. In addition, it is important that organizing sports activities in schools suitable for students' interests, wishes, and skills will both protect mental health and prevent unwanted behaviors. However, it is observed that the violence tendency is somewhat more complex and has a structure that is affected by numerous variables. Evaluating the previous studies, it is seen that there are both views and observations that the individuals regularly doing sports are less aggressive and have lower levels of violence tendency, as well as others demonstrating that there is no significant relationship between sports and aggression [48]. In the previous research, it was even demonstrated that the ones, who are highly watching heroic or violent movies, have higher violence tendency levels [12], which prove that there are numerous variables complicating an interpretation about the relation between the violence tendencies and doing sports. However, it is a fact that sports provide a positive contribution to the levels of psychological resilience [38] and has a positive effect on psychological structure.

Research findings demonstrated that there is a low-level and negative linear correlation between the violence tendency and psychological resilience (Table 10). These findings demonstrate that as the psychological resilience levels of the sample group increase, their violence tendency levels decrease. Participation in physical education activities and sport events has a number of positive effects on the psychological and mental structures of people [52]. Besides, it is known that participation in sport events strengthens people to cope with the problems they face in their professional lives, and it has eliminated the pessimistic psychological structure that arises from the unintended and monotone life conditions [53]. According to Şahin, Yetim and Çelik [54], since participation in physical activities and sports increases the physical endurance, it develops the strength of people to struggle against the difficulties. In the previous studies, it was demonstrated that it is associated with psychological structures such as depression, anxiety, and stress that can adversely influence the violence tendency [14-16, 55].

\section{Conclusions}

As the conclusion, in this study, in which the relationship was examined between the psychological resilience and violence tendency levels of individuals dealing with team and individual sports, it was concluded that, according to the gender and sports experience variables, the violence tendency and psychological resilience levels of the male and female athletes were similar; the violence tendency levels of adolescents dealing with team sports were higher; the violence tendency levels of the club athletes were lower and their psychological resilience levels were higher; there was a low-level, negative, and linear significant relationship between the violence tendency levels and psychological resilience levels of the sample group.

Since the impact of violence, particularly on the children 
at developmental ages, has a vital importance concerning violence in the society, it is significant that parents, educators, trainers, and physical education teachers should adopt proper approaches for supporting their students and athletes in stress, emotional changes, overcoming problems, and compliance problems.

\section{REFERENCES}

[1] WHO. (2006). Orientation programme on adolescent health for health-care providers, Geneva: World Health Organization, $\mathrm{CH}$.

[2] Negriff, S. \& Susman, E.J. (2011). Pubertal timing, depression, and externalizing problems: A framework, review, and examination of gender differences. Journal of Research on Adolescence, 21, 717-746.

[3] Masten, A. S. (2001). Ordinary magic: resilience processes in development. American Psychologist, 56(3), 227-238.

[4] Masten, A. S., \& Obradovic, J. (2007). Competence and resilince in development. Annals New York Academy of seciences, 1094, 13-27. DOI: 10.1196/annals.1376.003

[5] Olsson, C. A., Bond, L., Burns, J. M., Vella-Brodrick, D. A., \& Sawyer, S. M. (2003). Adolescent resilience: a consept analysis. Journal of Adolescence, 26(1), 1-11. DOI: 10.1016/S0140-1971(02)00118-5

[6] Garmezy, N. (1993). Children in poverty: Resiliency despite Risk. Psychiatry, 56(1), 127-136. DOI: 10.1080/00332747. 1993.11024627

[7] Craiy, R. (1968). The psychology of learning in the classroom. Newyork, NY: Mc Millian Comp.

[8] Akkaş, İ., \& Uyanık, Z. (2016). Violence against women. Nevşehir Hac1 Bektaş Veli University Journal of ISS, 6(1), p.32-42.

[9] Ayan, S. (2007). Violence against children of family (Unpublished doctoral dissertation). Cumhuriyet University İnstitute of Social Sciences, Sivas.

[10] Krug, E.G., Dahlberg, L.L., Mercy, J.A., Zwi, A.B., \& Lozano, R. (Eds.). (2002). World report on violence and health. Geneva, World Health Organization.

[11] Adak, N. (2000). Değişen toplumda değişen aile [Changing family in changing society]. Ankara: Siyasal kitapevi.

[12] Haskan, Ö. (2009). The violence tendency, loneliness and social support among adolescents (Unpublised master's thesis). Hacettepe University İnstitute of Social Sciences, Ankara.

[13] Balkıs, M., Duru, E., \& Buluş, M. (2005). The relationship between attitudes toward violance and self-efficacy, media, beliefs toward violance, peer group and sense of belonging to school. Ege Journal of Education, 6(2), 81-97.

[14] Rhodewalt, F., \& Zone, J. B. (1989). Appraisal of life change, depression, and illness in hardy and nonhardy women. Journal of Personality and Social Psychology, 56, 81-88. DOI:10.1037/0022-3514.56.1.81
[15] Motan, İ. (2002). Distinguishing anxiety and depression: Hardiness (Unpublised master's thesis). Middle East Technical University İnstitute of Social Sciences, Department of Psychology. Ankara.

[16] Kobasa, S. C., \& Puccetti, M. C. (1983). Personality and social resources in stress resistance. Journal of Personality and Social Psychology, 45(4), 839-850.

[17] Ülker Tümlü, G., \& Recepoğlu, E. (2013). The relationship between psychological resilience and life satisfaction of university academic staff. Journal of Higher Education and Science, 3(3), 205-213. DOI: 10.5961/jhes.2013.078

[18] Gökçe, B. (1993). The relationship between psychological strength and mental health in university students (Unpublised master's thesis). Ege University Institute of Social Sciences, Izmir.

[19] Terzi, S. (2008). The relationship between psychological hardiness and perceived social support of university students. Turkish Psychological Counseling and Guidance Journal, 3(29), 1-11. Retrieved from https://dergipark.org.t $\mathrm{r} / \mathrm{tr} / \mathrm{pub} / \mathrm{tpdrd} / \mathrm{issue} / 21449 / 229847$

[20] İlhan, A. (2017). The relationship between psychological resilience, dispositional flow and motivation in the exercise participants (Unpublished doctoral dissertation). Ege University Institute of Health Sciences, Izmir.

[21] Turkish Republic, Prime Ministry, Presidency of Family Research Association (1998). Aile İçinde ve Toplumsal Alanda Şiddet [Violence within the family and social area]. Bilim Serisi 113, Ankara: Başbakanlık Aile Araştırma Kurumu Yayınları [Prime Ministry Family Research Association Publications], p.47.

[22] Uysal, A. (2003). The effect of the education program against violence on student's conflict resolution, tendency to violence behaviors (Unpublished doctoral dissertation). Ege University Institute of Health Sciences, İzmir.

[23] Liebenberg, L., Ungar, M., \& Van de Vijver, F. (2012). Validation of the child and youth resilience measure-28 (CYRM-28) among canadian youth with complex needs. Research on Social Work Practice, 22(2), 219-226. DOI: $10.1177 / 1049731511428619$

[24] Liebenberg, L., Ungar, M., \& LeBlanc, J. C. (2013). The CYRM-12: A brief measure of resilience. Canadian Journal of Public Health, 104(2), 131-135.

[25] Arslan, G. (2015). Psychometric properties of child and youth resilience measure (CYRM-12): The study of reliability and validity. Ege Journal of Education, 16(1), 1-12. DOI: 10.12984/eed.23397

[26] Koç Yıldırım, P., Yıldırım, E., Otrar, M., \& Şirin, A. (2015). Investigating relationship between psychological resilience and self-construal in adolescents. Journal of Educational Sciences, 42, 277-297. DOI: 10.15285/ebd.58203

[27] Önder, A., \& Gülay, H. (2008). Resilience of 8 grade students in relation to various variables. Buca Faculty of Education Journal, 23, 192-197.

[28] Giles, J. W., \& Heyman, G. D. (2005). Preschoolers' use of trait-relevant information to evaluate the appropriateness of an aggressive response. Aggressive Behavior, 31, 498-509. DOI: $10.1002 / a b .20086$ 
[29] Gullone, E., \& Moore, S. (2000). Adolescent risk-taking and five-faktor model of personality. Journal of Adolescence, 23(4), 393-407. DOI: 10.1006/jado.2000.0327

[30] Scharf, S. (2000). Genders differences in adolescent aggression: An analysis of instrumentally (Unpublished doctoral dissertation). Central Michigan University, UK.

[31] Lopez, V. A., \& Emmer, E. T. (2002). Influences of beliefs and values on male adolescents' decisions to commit violent offenses. Psychology of Men and Masculinity, 3, 28-40. DOI: $10.1037 / 1524-9220.3 .1 .28$

[32] Thomas, S. P., \& Smith, H. (2004). School connectedness, anger behaviors, and relationships of violent and nonviolent American youth. Perspectives in Psychiatric Care, 40(4), $135-138$.

[33] Rahmati, F., \& Naimikia, M. (2012). The relationship between emotional intelligence and psychological hardiness in athlete and non-athlete students. Journal of Sport Management and Motor Behavior, 11(22), 141-148. DOI: 10.22080/JSMB.2015.998

[34] Babiss, L. A., \& Gangwisch, J. E. (2009). Sports participation as a protective factor against depression and suicidal ideation in adolescents as mediated byself-esteem and social support. Journal of Developmental \& Behavioral Pediatrics, 30(5), 376-384. DOI: 10.1097/DBP.0b013e318 $1 \mathrm{~b} 33659$

[35] Dishman, R. K., Hales, D. P., Pfeiffer, K. A., Felton, G. A., Saunders, R., Ward, D. S., ... Pate, R. R. (2006). Physical self-concept and self-esteem mediate cross-sectional relations of physical activity and sport participation with depression symptoms among adolescent girls. Health Psychology, 25(3), 396-407. DOI: 10.1037/0278-6133.25.3.396

[36] Duman, S., \& Kuru, E. (2010). The cooperation and determination of personal integration levels of Turkish students according to their sports participation level. Nigde University Journal of Physical Education and Sport Sciences, 4(1), 18-26.

[37] Selçuk, T. (2006). The participation and related problems of extracurricular school sport competitions of high school level students (for mersin city) (Unpublised master's thesis). Mersin University Institute of Health Sciences, Department of Physical Education and Sports, Mersin.

[38] Salar, B., Hekim, M., \& Tokgöz, M. (2012). To compare emotional state of individuals making team and individual sport 15-18 age group. Mehmet Akif Ersoy University Journal of Social Sciences Institute, 4(6), 123-135.

[39] Bülbül, A. (2015). Investigation and comparison of psychological resielence of the tennis and basketball players (Unpublised master's thesis). Gedik University Institute of Health Sciences, İstanbul.

[40] Avc1, R., \& Güçray, S. S. (2010). An investigation of violent and nonviolent adolescents' family functioning, problems concerning family members, anger and anger expression. Educational Sciences: Theory \& Practice, 10(1), 45-76.

[41] Bar, M. (2016). The effect of physical education and sports activities on psychological endurance and academic procrastination (Unpublished doctoral dissertation). Sakarya University Institute of Educational Sciences,
Sakarya.

[42] Patil, S. S. (2016). A comparative analysis of mental toughness in different level sportsmen. International Journal of Physical Education, Sports and Health, 3(2), 248-250.

[43] Slimani, M., Miarka, B., Briki, W., \& Cheour, F. (2016). Comparison of mental toughness and power test performances in high-level kickboxers by competitive success. Asian Journal of Sports Medicine, 7(2), 1-7. DOI: 10.5812/asjsm.30840.

[44] Masten, A. S., \& Reed, M. G. (2002). Resilience in development. In C.R. Snyder \& S.J. Lopez (Eds.), The Handbook of Positive Psychology (pp. 117-131). New York, NY: Oxford University Press.

[45] Özkara, A.B., Kalkavan, A., Alemdağ, S., \& Alemdağ, C. (2016). The role of physical activity in psychological resilience. Baltic Journal of Sport Health Science, 3(102), 24-29. DOI: 10.33607/bjshs.v3i102.62

[46] Karagün, E. (2015). Violence tendencies of high school students: an examination in terms of exposure to violence, participation in sports and socio-demograpic attributes. Education Research and Reviews, 10(1), 29-35. DOI: 10.5897/ERR2014.2002

[47] Demir, Ö.O., \& Aliyev, R. (2019). Resilience among Syrian university students in Turkey. Turkish Journal of Education, 8(1), 33-51. DOI: 10.19128/turje.454138

[48] Varhan, S. (2016). A study on the effects of the 12-week sports activities done by single-parent students in secondary schools on the tendency to aggression and violence (Unpublised master's thesis). Dumlupınar University Institute of Health Sciences, Kütahya.

[49] Mesutoğlu, C. (2012). The relationship among self-construal, family functioning and sibling number in terms of gender in high school students (Unpublised master's thesis). Middle East Technical University İnstitute of Social Sciences, Ankara.

[50] George, H. (1979). Sport and the social science. The American Academy of Political and Social Science, 445(1), 1-14. DOI: $10.1177 / 000271627944500103$

[51] Edward, H. (1973). The sociolgy of sport. Newyork, NY: Dorsey Press.

[52] Keskin, Ö. (2014). Effects of physical education and participation to sports on social development in children. International Journal of Multidisciplinary Academic Research, 1(1), 1-6.

[53] Küçük, V., \& Koç, H. (2004). Relationship between human and sports in psycho-social development process. Dumlupınar University Journal of Social Sciences, 10, 131-141.

[54] Şahin, M., Yetim, A. A., \& Çelik, A. (2012). Physical activity and sport as a preventive factor in building resilience. The Journal of Academic Social Science Studies, 5(8), 373-380. DOI: 10.9761/JASSS_405

[55] Lambert, V. A., \& Lambert, C. E. (1999). Psychological hardiness: State of Science. Holistic Nursing Practice, 13(3), 11-19. 